\title{
A Kind of Research on Regenerative Braking Algorithm of Hybrid Electric Vehicle
}

\author{
Z.L. Liao \\ Department of Control Engineering \\ Academy of Armored Force Engineering \\ Beijing, China \\ Q. Gao \\ Department of Control Engineering \\ Academy of Armored Force Engineering \\ Beijing, China
}

\author{
P. Fan \\ Bureau of Military Agent of Transport Military Agent's \\ Section of Nanjing Area \\ Nanjing, China \\ R.F. Hu \\ PLA Agency in No.201 \\ Beijing, China
}

\begin{abstract}
Discussed an energy recovered method of the regenerative braking system of a Parallel Hybrid Electric Vehicles (PHEV), and promoted the performance, efficiency, and reliability in a minimal cost. Discussed the generative braking algorithm based on the simulation of PHEV in MATLAB.
\end{abstract}

Keywords-generative braking; hybrid electric; controlling algorithm

\section{INTRODUCTION}

The tire is driven by a vehicle electric system, which is consists of a lot of nonlinear system, such as power plant, drive system, differential system and shaft system. In addition, some other attachments such as steering system and braking system are attached to the power plant. The vehicle electric system, which is a nonlinear dynamic composite system, is formed by electrical, mechanical, chemical, and thermal equipment. It is mainly used to supply energy.

Hybrid Electric Vehicle (HEV) combined Electric Vehicle's (EV) electric system and traditional electric system. The PHEV, which included electric driven system and traditional electric system, supplied energy to the tires. Through the auxiliary power unit, it can be combined with traditional electric vehicle driven system. The HEV can prolong performance envelope and the fuel economy. Meanwhile, it can also reduce the exhaust gas emission.

Most HEVs used the traditional braking system and RBS at the same time. Traditional braking system included the friction brake drum or disc brake, and driven by the hydraulic system. RBS used the motor to supply negative torque to stop the vehicle and change the kinetic energy into electricity energy to charge the battery. In the braking time of EV or HEV, the kinetic energy loss can be recovered effectively by controlling the motor in a power generation working condition. The recovery energy can be saved in storage devices.

\section{Generative BRAKING CONTROLLING AlgORITHM}

The generative braking controlling algorithm adopted MATLAB to build the models and coding in auto. The code will be downloaded into the controller and test tools. Not only the hydraulic braking torque, but also the parallel braking system produced a generative braking torque to the tires. The braking order delivered by motor controller which based on coordinated controller doesn't included hydraulic brake. Hence, it can recycle the vehicle kinetic in maximum. The hydraulic braking torque was delivered by the driver when he steps on the brake to give a electric signal. The generative braking order was delivered by braking controller and coordinated controller. Meanwhile, the electric braking torque can strength the hydraulic braking torque and the parallel brake was decided by total braking demand function.

In the parallel braking system, the central controller can calculated the torque which was plus by electric braking torque and hydraulic braking torque based on a given function. The fellow equation describes the relationship between hydraulic braking torque and electric braking torque.

$$
\mathrm{T}_{e}=\left[\frac{\left(g^{\prime} s \cdot R_{w} \cdot W_{v}\right)-\left(2 \cdot B F_{f} \cdot P_{f}\right)-\left(2 \cdot B F_{r} \cdot P_{r}\right)}{g_{4 \times 4} \cdot g_{\text {axle }}}\right]
$$

The braking torque of tire was decided by braking controller as fellow.

$$
\begin{array}{lll}
P_{f}=P_{m c}, P_{r}=P_{m c} & \text { for } & P_{m c} \leq X \\
P_{r}=X+\delta\left(P_{m c}-X\right) & \text { for } & P_{m c}>X
\end{array}
$$

The electric braking torque which is plus into hydraulic braking torque was decided by motor torque features, surface state of road and tires, brake pedal stroke and static braking force.

The static braking force was decided by the picture of static braking force. The picture including the brake shutting features in different roads, braking ratio in front and back, and the vehicle's deceleration state. The braking shutting curves is the 
maximum braking torque in different roads of the braking torque as the Figure1 shows.

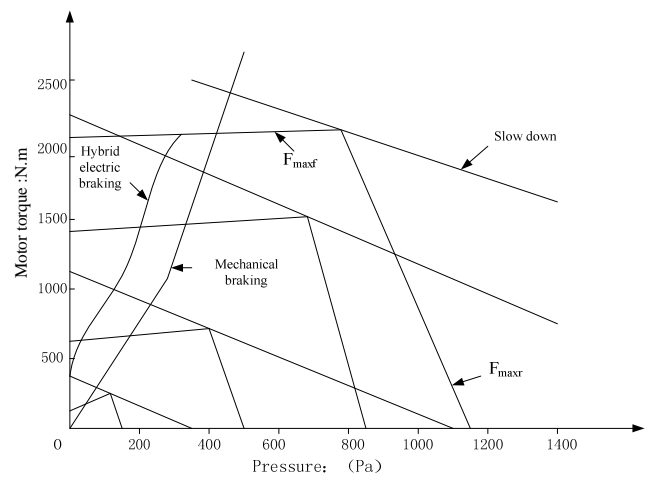

FIGURE I. STATIC BRAKING FORCE CURVE.

In Figure1, the vertical coordinate means the front braking torque, in the other hand, the abscissa means the back braking torque. And their intercepts were given as fellow.

$$
\begin{gathered}
F_{\text {max } f}=\frac{\mu_{p}\left(W_{v} B / L\right)}{1-\mu_{p} H / L} \\
F_{\text {max } r}=\frac{\mu_{p}\left(W_{v} A / L\right)}{1+\mu_{p} H / L} \\
\text { slope }_{f \text { max }}=\frac{\mu_{p} H / L}{1-\mu_{p} H / L} \\
\text { slope }_{r \text { max }}=\frac{-\mu_{p} H / L}{1+\mu_{p} H / L}
\end{gathered}
$$

The braking torque was influenced by the braking force, and the value was given as fellow.

$$
\begin{gathered}
F_{\text {rear }}=\frac{2 \cdot B F_{r} \cdot P_{r}}{R_{w}} \\
F_{\text {front }}=\frac{2 \cdot B F_{f} \cdot P_{f}}{R_{w}}
\end{gathered}
$$

The total braking force equals the front braking force plus the back. In addition, its value equals the vehicle's quality multiply the vehicle's deceleration. The equation was given.

$$
F_{r}=F_{\text {front }}+F_{\text {rear }}=\left(\frac{W_{v}}{g}\right) a_{x}
$$

If the driver given a deceleration about $0.6 \mathrm{~g}$ on a road with a road condition about $0.8^{\mu}$, the front and back braking force would meet the braking demand in maximum based on a steady driving, only if the braking force hold on the triangle deceleration area and correspond the maximum braking torque on the road about $0.8 \mu$.

The optimal generative braking control strategy can choose a better ratio to fit in all the design aims, such as the brake stopping distance, the maximum braking force and so on. It can make the total brake force gets the max value on the demanding frontier and get to use the generative brake as well.

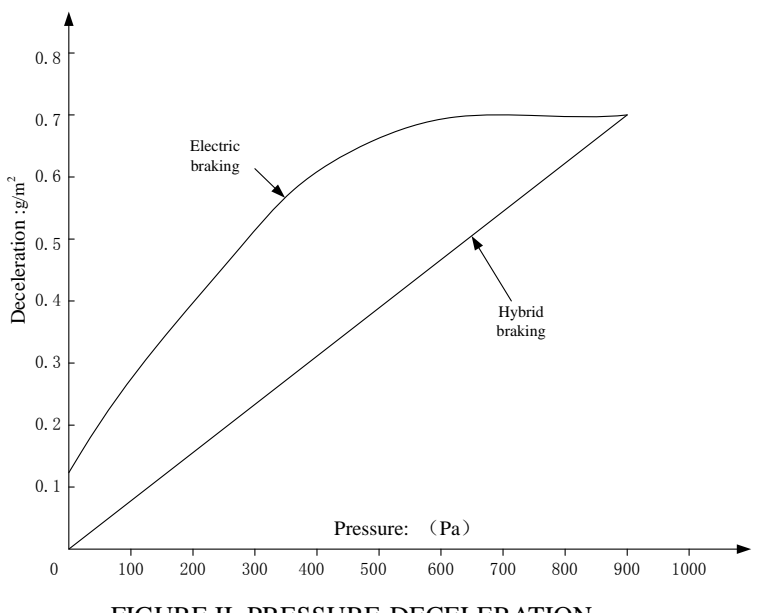

The picture about pressure and deceleration decided the relationship between the electric braking torque which is plus to the mechanical and the road. The mechanical curve can be the function of pressure-brake curve. It was shown as the fellow equation.

$$
\text { decel }=\frac{2 \cdot B F_{f} \cdot P_{f}+2 \cdot B F_{r} \cdot P_{r}}{W_{v} \cdot R_{w}}
$$

In order to recover the energy, the coefficient of road adhesion must get close to $0.7^{\mu}$. Once the coefficient of road adhesion get higher than $0.8^{\mu}$, the braking force will get to the peak value too fast to recover the energy. Usually, the drivers will give a braking force about $0.2 \mathrm{~g}$ when they meet a red light. At this moment, the braking controller has distributed the electric braking torque in maximum limitation to produce an energy feedback.

The braking force inside the tire consists of motor braking torque and hydraulic braking torque, and the relationship between electric braking torque and tire braking torque. It was shown as Figure3. 


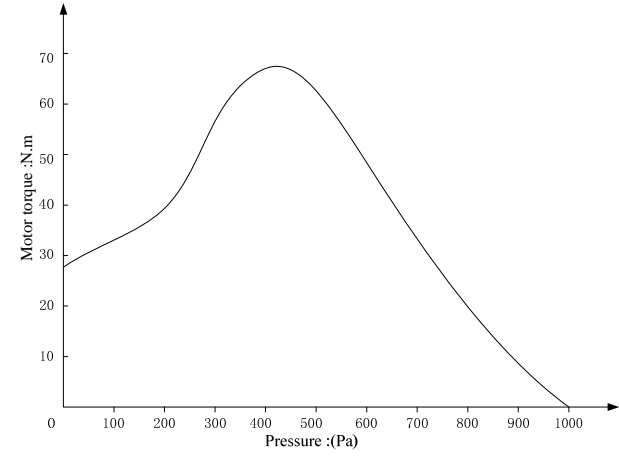

FIGURE III. GENERATIVE BRAKING TORQUE.

The value of the motor's positive and negative torque was given by the motor controller. The given value of the motor torque was shown as fellow.

$$
\begin{aligned}
& T_{\text {available }}=\frac{P_{\text {rated }}}{\omega_{m}} \cdot 5252, \quad \omega_{m}>\omega_{b} \\
& T_{\text {available }}=T_{\text {rated }}, \quad \omega_{m} \leq \omega_{b}
\end{aligned}
$$

The given value of the useful feedback braking torque was given by the fellow equation.

$$
\begin{aligned}
& T_{\text {regenavail }}=\frac{P_{\text {rated }} \cdot 5252}{\omega_{m}}-T_{\text {compression }}, \vdots \omega_{m}>\omega_{b} \\
& T_{\text {regenavail }}=T_{\text {rated }}-T_{\text {compression }}, \vdots \omega_{m} \leq \omega_{b}
\end{aligned}
$$

The motor cannot supply enough negative torque to recover the energy when the vehicle working on a low speed. It will be stopped only by electric brake when the electric braking torque can fit in and the energy was recovered in maximum limitation. However, when the energy storing device was full, the braking torque was supplied by mechanical brake.

$$
T_{\text {compression }}=\frac{g^{\prime} s \cdot R_{w} \cdot W_{v}}{g_{4 \times 4} \cdot g_{a x l e}}
$$

Motor's driven torque is a nonlinear function of the motor's rotate speed. And the loss torque produced by inverter was also a function of the motor's rotate speed. The function was shown as the equation.

$$
\begin{aligned}
& T_{m}=\frac{P_{\text {rated }} \cdot 5252}{\omega_{m}} \quad \omega_{m}>\omega_{b} \\
& T_{m}=T_{\text {rated }} \quad \omega_{m} \leq \omega_{b}
\end{aligned}
$$

In these equations, there is another equation.

$$
T_{e}-T_{m} \cdot 1.3558=J_{m} \omega_{r}
$$

The load current of inverter is a function of both the motor's rotate speed and the motor torque and the voltage of bus line. It can be shown as fellow.

$$
I_{\text {load }}=\frac{T_{m} \cdot \omega_{r}}{e_{t b}} \cdot \frac{1.3558}{\eta}
$$

The equation was shown as fellow equationwhen the motor working on the generative braking condition.

$$
I_{\text {load }}=\frac{T_{m} \cdot \omega_{r}}{e_{t b}} \cdot \eta \cdot 1.3558
$$

The controlling algorithm needs the fellow inputs. Such as braking switch signal, braking pedal location, motor's rotate speed, the estimating value of motor's torque, the logic value of choosing mode and the value of Iq. The output signals including the demanding ratio value of hydraulic braking torque and the demanding value of Iq in electric brake.

The drivers have two choices. One is the total electric drive and another is the hybrid drive. The controlling strategy decided the working mode, which including driven by engine, driven by motor or driven by both the two, when the vehicle working on hybrid mode. The motor will work alone when the vehicle brake in the generative mode. The engine will work alone when the traditional hydraulic braking. When the vehicle brakes in hybrid driven mode, the engine's velocity slows down to the idling. The driver should shift the gear to keep the power transmission. The linear brake should be used to avoid discontinuous brake when the generative brake changed to hydraulic brake.

The accelerated position of the pedal will be auto detected by sensor, which instead of the accelerated signal of the driver. If the position of pedal performed abnormal, or if the braking signal opened, the vehicle would be stopped by the empty signal of acceleration. This order was delivered through a NOT gate signal. This signal and the braking signal became a braking logic through an OR gate. This signal is a high level when the applied brake working.

\section{Test DATA AND Simulation Result}

The initial value of the test is set as $30 \mathrm{~km} / \mathrm{h}$. The result is gotten through modeling and simulating by Matlab. The parallel hybrid electric vehicle brakes when the vehicle is driven by electromotor, driven by engine and electric or driven by engine.

The Figure4 indicates that when electric brake works alone, the braking torque is supplied by electromotor. When the vehicle is getting close to stop, the braking torque is supplied by mechanical braking. The Figure5 indicates that when electric and engine work together, the braking torque is 
supplied by electric braking and mechanical braking. The Figure6 indicates that when the engine works alone, the braking torque is supplied by mechanical braking.

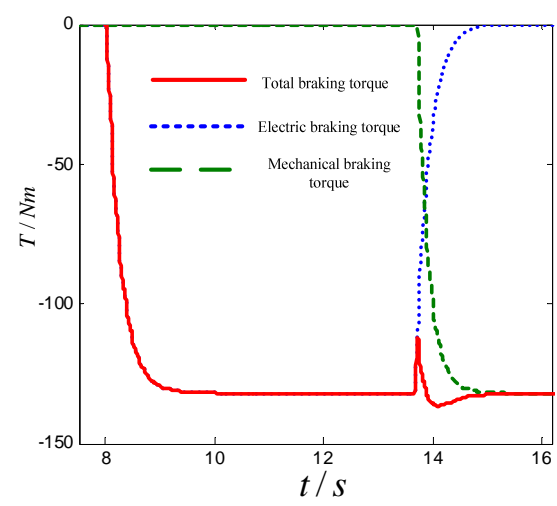

FIGURE IV. DRIVEN BY ELECTRIC.

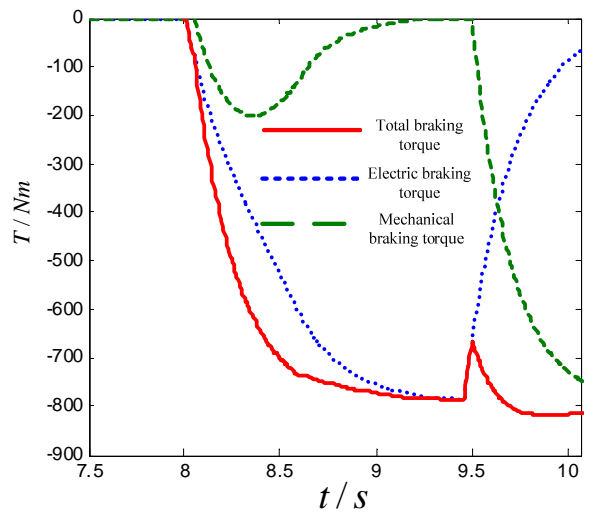

FIGURE V. DRIVEN BY ENGINE AND ELECTRIC.

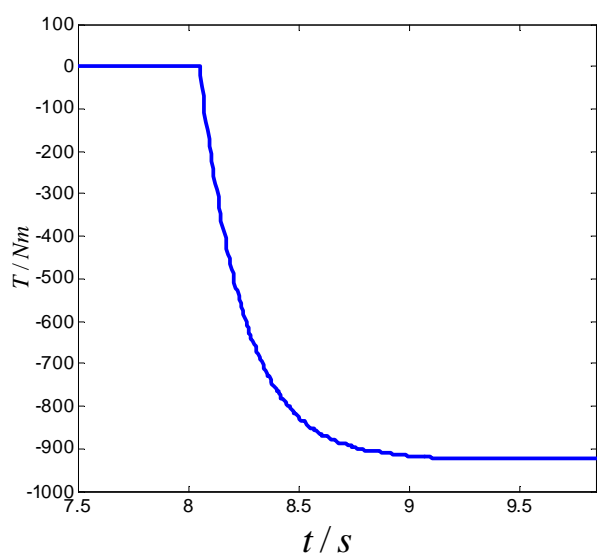

FIGURE VI. DRIVEN BY ENGINE.

\section{SUMMARY}

A new improved scheme on parallel hybrid electric vehicle is discussed in this article. It can improve the fuel efficiency of the engine, and enhance the energy recovery at the greatest extent when braking. The regenerative braking effectively improves the braking through reasonable brake control strategy.

\section{REFERENCES}

[1] Xue-guo AN, Nian-yu Li.The Forward Appliance and Challenge of Military Electric/Hybrid Electric Vehicle:1st[J].Foreign Tanks. 2008(7):45-49

[2] Ke-mao Zang. Study on the All-electric Technology of Land Warfare Platform[J]. Journal ofAcademy of Armored Force Engineering. 2011, 25(1):1-7

[3] Loic.B.D, Alain.B, Olivier.P, Marie.P. Simulation model of military HEV with a highly redundant architecture [J].IEEE Trans on vehicular technology. 2010, 59(6):2654-2663.

[4] Ming-hui Hu. Study on Energy Management Strategy for Mild Hybrid Electrical b Vehicle with CVT.Chongqing University,2007

[5] Donghyun Kim, Sungho Hwang, Hyunsoo Kim. Vehicle Stability Enhancement of Four-Wheel-Drive Hybrid Electric Vehicle Using Rear Motor Control[J]. IEEE Transactions on Vehicular Technology. 2008, 57(2): 727-735. 